\title{
Basal cell carcinoma of penis: case report
}

\author{
M Z C SULAIMAN,* S V POLACARZ, $†$ PE PARTINGTON* \\ From the Departments of *Genitourinary Medicine and $\nmid$ Pathology, Royal Hallamshire Hospital, Sheffield
}

SUMMARY Basal cell carcinoma of the penis is rare. A patient who presented with a penile and scrotal ulcer due to basal cell carcinoma is reported. Wide local excision and split skin grafting were performed to excise the lesion completely.

Primary basal cell carcinoma is rarely found on the penis, and reports on only 11 patients have been published.' The patient discussed here represents the twelfth reported case.

\section{Case report}

A white man aged 49 presented in January 1987 with a

large ulcer at the base of his penis, which had become grossly swollen over the preceding five days. The lesion had first appeared as a blister at the base of the dorsum of the shaft and, five years earlier, developed into an ulcer that gradually increased in size but otherwise caused no symptoms. There was no history of extramarital sexual contact, sexually transmitted diseases, dermatological disorders, or exposure to
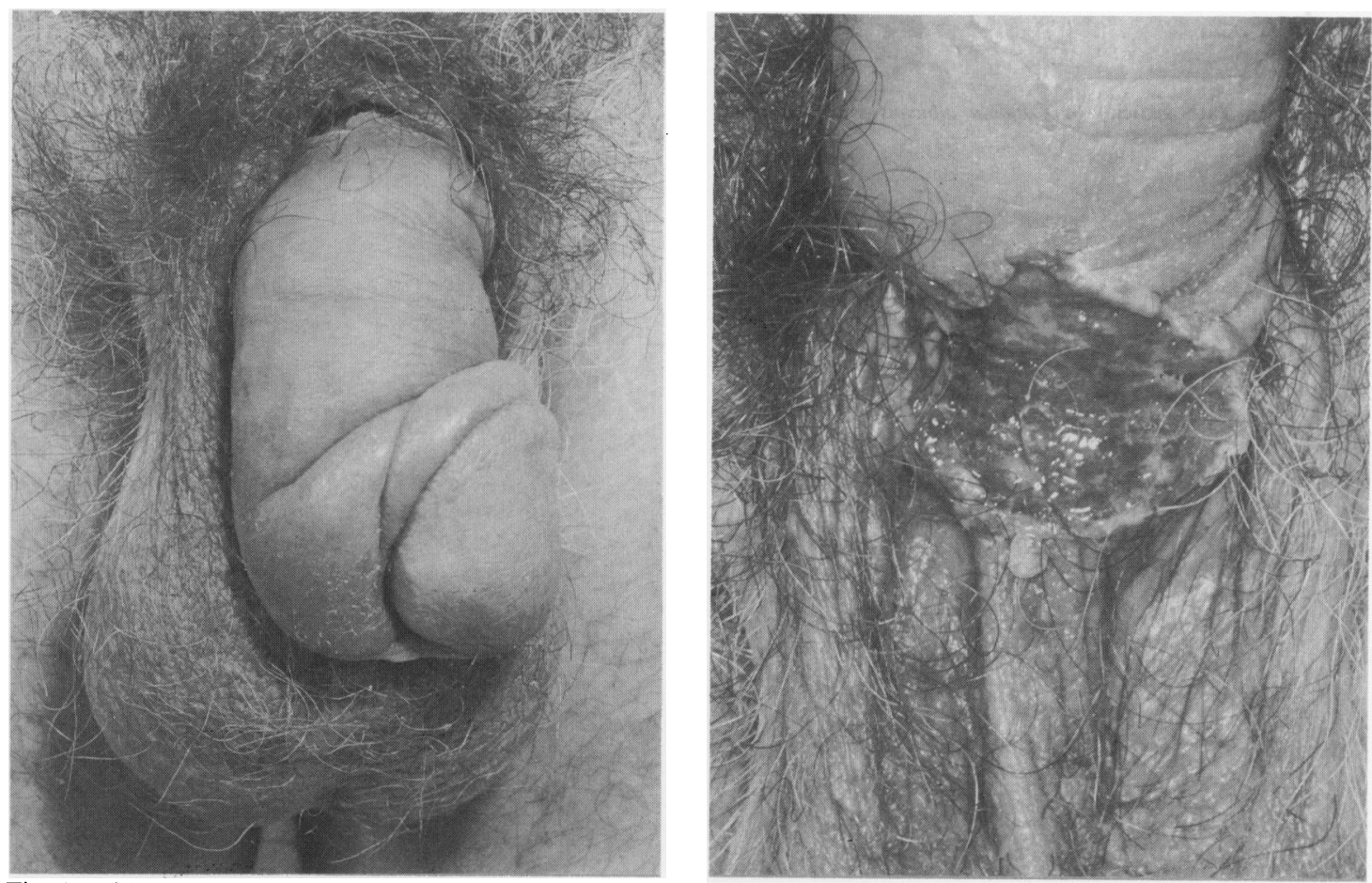

Figs 1 and 2 Basal cell carcinoma ulcer almost circumscribing penis and causing oedema of penis and adjacent scrotum.

Address for reprints: Dr M Z C Sulaiman, Department of Genitourinary Medicine, Northgate Hospital, Great Yarmouth, Norfolk NR30 1 BU.

Accepted for publication 10 May 1987 ultraviolet light, although there was a possibility of zip trauma. The patient worked as a painter and decorator, but had not been exposed to toxic chemicals. 

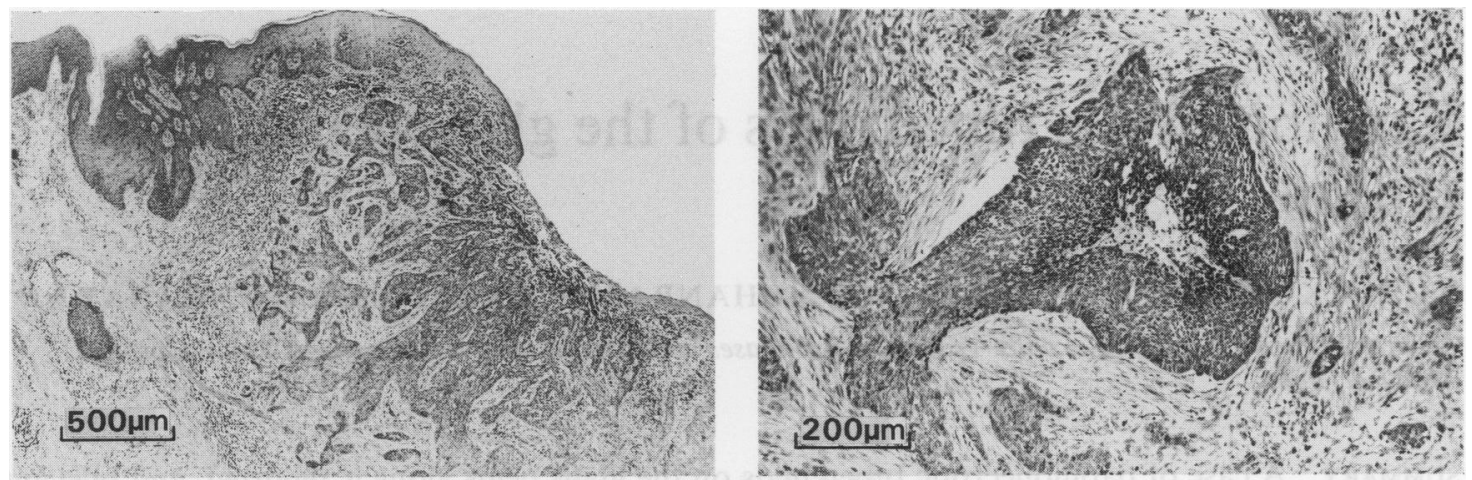

Fig 3 Characteristic morphology of basal cell carcinoma at low power (left), showing central ulceration and basaloid tumour cells infiltrating desmoplastic stroma, and at high power (right), showing nuclear palisading at periphery of groups of tumour cells (haematoxylin and eosin).

Examination showed a deep, infected, ulcerated lesion $5 \mathrm{~cm} \times 3.5 \mathrm{~cm}$ with rolled edges. The lesion almost circumscribed the base of the penis, which was uncircumcised. The penis and the adjacent scrotum were oedematous (figs 1 and 2). The inguinal lymph nodes were mobile and not enlarged, and no other cutaneous lesions were noted.

Culture of the ulcer exudate yielded a heavy growth of anaerobes. Screening tests for sexually transmitted pathogens gave negative results, and a chest $x$ ray showed no abnormality.

Biopsy of the ulcer showed, at low power (figure 3, left) extensive central ulceration and basaloid tumour cells infiltrating a desmoplastic stroma. At higher power (fig 3, right) there was a striking tendency for nuclear palisading at the periphery of groups of tumour cells. Tissue clefts were also seen adjacent to these groups in some areas. These appearances are considered to be pathognomonic of infiltrating basal cell carcinoma.

Penectomy and irradiation were considered because of the size of the lesion, but the patient wished to preserve his phallus. As radiotherapy would have prolonged the oedema considerably, the ulcer was excised with a margin of unaffected skin. Primary skin closure was not possible, so a split skin graft from the thigh was applied to the denuded area. Histopathological examination confirmed that the lesion had been excised completely.

Convalescence was uneventful, and at outpatient review seven weeks later the wound had healed even though the prepuce was still oedematous.

\section{Discussion}

Several authors have reviewed published reports of primary basal cell carcinoma of the penis. ${ }^{1-3}$ Our patient differed from those previously reported in that his ulcer was larger and had extended to the adjacent scrotum. Although carcinoma was suspected clinically, it was necessary to exclude a sexually transmissible infection. Biopsy before treatment was also essential to rule out the more common squamous cell tumour, which may have a similar clinical appearance but would require more radical treatment.

Complete cure can be expected, but close follow up will be maintained to exclude local recurrence or spread of the tumour to regional lymph nodes.

We thank Dr G R Kinghorn, for permission to report the case, and Mrs C Gibson for typing the manuscript.

\section{References}

1 McGregor DH, Tanimura A, Weigel JW. Basal cell carcinoma of penis. Urology 1982;20:320-3.

2 Fegen JP, Beebe D, Persky L. Basal cell carcinoma of the penis. $J$ Urol 1970;104:864-6.

3 Hall TC, Britt DB, Woodhead DM. Basal cell carcinoma of the penis. J Urol 1968;99:314-5. 